\title{
Addressing overnutrition and physical inactivity: past, imperfect, future tense
}

Johan Faskunger' and Erik Hemmingsson 2,3

'Unit for Preventive Nutrition, CNT at Novum, Karolinska Institutet and Stockholms Läns Landsting, Huddinge, Sweden; ${ }^{2}$ Obesity Unit, Karolinska Institutet at Huddinge University Hospital, Sweden; ${ }^{3}$ Department of Exercise and Health Sciences, University of Bristol, UK

\section{Nutrition, physical activity and behaviour change - a staple work diet for future health professionals}

"The best time to plant a tree was 25 years ago."

Chinese proverb.

Overnutrition and physical inactivity are behaviours that over time will help manifest diseases, such as obesity (defined as a body mass index above $30 \mathrm{~kg} \mathrm{~m}^{-2}$ ) and type II diabetes, causing massive costs to society and suffering to individuals. If left untreated, obesity increases the risk of early death, type II diabetes, coronary heart disease, cancer, depression, anxiety, sleep apnoea and low quality of life. Equally disturbing is the speed at which obesity is spreading. Rasmussen et al. (1) recently found that the incidence of obesity in Swedish military conscripts quadrupled from 1971 to 1995. Other Nordic obesity incidence data from Finland (2) and Denmark (3) mirror this worrying development.

National health services are now increasingly treating behaviourally triggered diseases that in theory are highly preventable, but difficult to manage in practice (4). Obesity is a good example of such a modern lifestyle-related disease where health workers would benefit from multidisciplinary training, including nutrition, physical activity and behaviour modification. The need for knowledge and skills on how to implement behaviour modification is critical, since health information alone is a poor determinant of behavioural change. All of these factors put together serve to highlight the urgency in educating and employing highly resourceful health workers who can work with altering people's behaviour both in societies on a population level, and in the healthcare system on an individual level.

\section{The skills that make a difference}

What is becoming increasingly clear is that the traditional and discipline-specific education of health professionals appears outdated in dealing with behavioural change (5). Current and future education for health workers, whether it is in the area of public health, health promotion, nutrition, exercise or medicine, demands greater attention to issues related to both physical activity and nutrition, as outlined by Sjöström et al. (6). However, training and education cannot be restricted to traditional subject knowledge. Key skills to implement and assist behaviour modification include: motivational interviewing, cognitive behaviour therapy and group counselling, health communication, including interactive technologies and the Internet, and implementation of promising research findings.

Regardless of subject area or main interest, the future health professional will be required to deal with issues of attitude and behaviour change, such as strengthening clients' self-efficacy, overcoming perceived barriers and relapse, recruiting and using social support, increased self-monitoring of behaviour and providing cues for action (7). For example, a dietician using the above strategies in patient counselling, as opposed to just providing subject information, may expect more effective promotion of healthy eating and physical activity.

Apart from the individual approach described above, interventions in both health care and public health will need to adopt a more proactive approach. This implies trying more actively to reach large groups of people in everyday life, rather than passively waiting for interested customers or single patients in need. The real challenge in proactive intervention lies in reaching the segment of the population that is most prone to developing these lifestyle diseases. This segment of the population is often characterized by low education and low social class (8), and may therefore be less likely to respond to health intervention. Interactive health communication may bring an opportunity to overcome this barrier, with its potential for $24 \mathrm{~h}$ access and nonjudgemental support tailored to the user's needs (9). 
Health workers will also need a clear understanding of current health research, and skills to implement promising findings. For example, as early as 1980 an American study (10) showed that stair use could be increased simply by hanging a sign next to the escalators urging people to take the stairs for the purpose of improving health status - a method that was relatively cheap and simple to implement. This was later replicated in British studies with positive results e.g. (11).

When such positive health-promotion methods are found it is puzzling to discover the general absence of such signs in our societies. This shows that proven methods to improve public health are not always applied - a clear priority for modern public health workers.

In addition to implementing proven health-promotion methods in societies, health workers will benefit from being creative and inventive in the way they seek to counter overnutrition and inactivity. This could, for example, mean lobbying for changed legislation on health promotion in the workplace, but also simple things such as educating food outlets on low-fat cooking. Other examples are liaising with town planners, where the objective would be to create safe and stimulating spaces, and workplaces where people can perform physical activity and exercise.

The emphasis on creativity may sound vague, but given the speed at which obesity and other lifestylerelated diseases are spreading, there may not be sufficient time to wait for research evidence on all possible aspects before taking action. Moreover, research on how changes to our society affect behaviour is time consuming and difficult to carry out for practical and financial reasons.

\section{Tackling an "obesity toxic" environment}

Even if there were more approaches to helping people to change diet and physical activity habits, there is still what experts now call our current "obesity toxic" environment. The abundance of cheap and palatable food, often high in fat, clearly works against health workers. From the point of view of physical inactivity, the number of cars per household has increased, as has the time spent watching television. Jobs are increasingly sedentary, and labour-saving devices, such as dishwashers, computers and electric toothbrushes, appear to be increasing. People's current lifestyle and environment undoubtedly invite a sedentary lifestyle, often spent in front of a television or computer screen.

\section{A call for increased resources}

The best time to plant a tree may have been 25 years ago, but the second best time is now. As a step in the development of the education of future health professionals there is a great need for an increase in government spending to existing programmes and courses, and research on nutrition and physical activity. Until this happens, it is unlikely that health workers will be able to make significant inroads into changing the health-damaging lifestyles widely prevalent in today's Nordic countries. Most health professions, such as physiotherapists, dieticians, nutritionists, physicians and nurses, already face these challenges in their day-to-day clinical life. We would all benefit from giving them a realistic chance.

\section{References}

1. Rasmussen F, Johansson M, Hansen HO: Trends in overweight and obesity among 18-year-old males in Sweden between 1971 and 1995. Acta Paediatr 1999;88:431-7.

2. Pietinen P, Vartiainen E, Mannisto S: Trends in body mass index and obesity among adults in Finland from 1972 to 1992. Int J Obes 1996;20:114-20.

3. Thomsen BL, Ekström CT, Sörensen TI: Development of the obesity epidemic in Denmark: cohort, time and age effects among boys born 1930-1975. Int J Obes 1999;23:693-701.

4. Glenny AM, O'Meara S, Melville A, Sheldon TA, Wilson $C$ : The treatment and prevention of obesity: a systematic review of the literature. Int J Obes 1997;21:715-37.

5. Hoppe R, Ogden J: 'Practice nurses' beliefs about obesity and weight related interventions in primary care. Int $\mathbf{J}$ Obes 1997;21:141-6.

6. Sjöström M, Yngve A, Poortvliet E, Warm D, Ekelund $\mathrm{U}$ : Diet and physical activity - interactions for health; public health nutrition in the European perspective. Public Health Nutr 1999;2(3A):453-9.

7. Hemmingsson E, Page A, Fox K, Rössner S: Influencing adherence to physical activity behaviour change in obese adults. Scand J Nutr/Näringsforskning 2001;45:114-9.

8. Lissner L, Johansson SE, Qvist J, Rössner S, Wolk A: Social mapping of the obesity epidemic in Sweden. Int J Obes 2000;24:801-5.

9. Street RL Jr, Gold WR, Manning T, eds. Health promotion and interactive technology: theoretical applications and future directions. Mahwah, NJ: Lawrence Erlbaum Associates, 1997.

10. Brownell KD, Stunkard AJ, Albaum JM: Evaluation and modification of exercise patterns in the natural environment. Am J Psychiatry 1980;137:1540-5.

11. Blamey A, Mutrie N, Aitchison T: Health promotion by encouraged use of stairs. Br Med J 1995;311:289-90.

\section{Johan Faskunger}

Unit for Preventive Nutrition, CNT at Novum, Karolinska

Institutet and Stockholms Läns Landsting, SE-14I57 Huddinge,

Sweden.

E-mail: johan.faskunger@prevnut.ki.se 